\title{
Study of the Effective Factors on Air Pollution in Iran Cities
}

\author{
Dr. Saeede Safari \\ Assistant Professor, \\ Islamic Azad University Central Tehran Branch.
}

\begin{abstract}
Nowadays, air pollution in cities with regard to its harmful outcomes has been turned in to one of the serious challenges in urban management. Carbon dioxide emission is one of the most principal factors in the environmental pollution, the world efforts are concentrated to reduce it due to its devastating effects on climatic change and global warming. In the current research, the effective factors on air pollution in Iranian cities were studied, considering CO2 emission level as the pollution index in the period 1993-2013 and for analyze effective factors, econometrics models were applied. The research findings demonstrated, with increase per capita income and Urbanization rate, air pollution, has been increased. Also Study of the effective factors on cities air pollution in Iran showed that per capita oil and natural gas products consumptions have a significant positive effect on $\mathrm{CO} 2$ emission while per capita natural gas consumption had a more important effect (4.04\% compared to 3.4\%). Therefore, important sources of energy in Iran, which oil and natural gas products, were found as the most dominant factors in air pollution. Thus, the necessity of current energy carriers' replacement by clean energy sources as solar energy and geothermal energy is emphasized.
\end{abstract}

Keywords: Air pollution, Fossil fuels, Greenhouse gases.

Jel cod: Q56, R4, C22

\section{1-Introduction}

In the recent decades, environmental issues have been among the important challenges in the national and global policies due to the increased greenhouse gas emissions. Greenhouse gases increase such as $\mathrm{CO}_{2}$ led to the phenomena as climatic change, global warming, depletion of ozone shield, and melting polar ice sheets. However, the effects of greenhouse gases increase as $\mathrm{NOX}, \mathrm{CO}$, and $\mathrm{SO}_{2}$ are observed in the national and regional scales like acidic rain, sanitary and hygienic dangers to human being and other creatures, the effects of $\mathrm{CO}_{2}$ emission is considered on the global scale. International seminars and protocols like Rio conference, Kyoto protocol, and Copenhagen summit all indicate the importance of this issue in the entire world and account for the efforts to make policies in order to control global warming and climatic change - which greenhouse gases increase have had a significant role and among them, $\mathrm{CO}_{2}$ is the most important one (Karbasi \& Rahimi, 2000:2). According to the World Bank reports of the environmental pollutants causing climatic change, $76 \%$ of the total greenhouse gases were allocated to carbon dioxide in 2010. $\mathrm{CO}_{2}$ emission had a rising trend in Iran as well and has been increased from 302 million tons in 2001 to 587 million tons in 2013; while carbon dioxide share among all the polluting and greenhouse gases was $98 \%$.(E.B.S,2013)

In accordance with Kyoto protocol, Iranian government is obliged to reduce the total carbon dioxide gas emission. The extensive energy consumption and utilization of fossil fuel in various economy sectors are the major reasons of greenhouse gas emission.

The urban lifestyle and consumption patterns in large cities enhance energy resource usage in a higher amount than other smaller cities. As cities are developed and enriched, the demand for urban infrastructure, transportation, and individual resource use all grow; consequently, the challenges regarding the energy consumption and pollution emission are emphasized (Pomny \& Kaniko, 2010).

Carbon dioxide is considered as the indicator of environmental pollution due to its particular importance in air pollution and intensification of global warming in most of the experimental studies. $\mathrm{CO}_{2}$ emission and global warming resulted in climatic change which might pose noticeable risks to physical infrastructure, city societal context, and safety of societies; therefore, the research objective is to investigate the effective factors on air pollution of cities in Iran based on $\mathrm{CO}_{2}$ emission indicator.

\section{2- Literature review and research background}


According to the definition by the superior council of environmental protection, air pollution involves existence of one or several pollutants in the open air in such an amount and duration that changes the air quality so that it dangers human being and other creatures' lives, plants, as well as built environment. Public transportation services, thermo-electric power plant, domestic, agricultural, and fishery industries are the air pollution sources.

There are plenty of evidences of the positive correlation between energy consumption and improvement of economic macro variables. Improvement of the economic macro variables leads to pollution spread due to energy consumption increase. Gross domestic product, is one of the significant economic variables considered as an indicator for the economy growth measurement. The correlation between economic growth and environmental pollution in the last two decades has been widely analyzed by statistical methods.

The practical framework for the aforesaid evaluation is based on the Environment Kuznets Curve (EKC) theory which reveals the correlation between environmental index and the per capita income. According to this theory stated by Grossman and Krueger (1991) and became known by the global development report of the world bank in 1992, the correlation between per capita income and environment deterioration indices is an inverse $U$. Based on this theory, the correlation between economic growth and environmental quality, either positive or negative, is not constant along the country's development; in the beginning, pollution increases due to per capita income increase, but it later decreases after reaching a specific level of per capita income. Indeed, as a country arrives at a situation that the demands for a cleaner environment are enlarged and the efforts to achieve more efficient infrastructure broadens, the sign of correlation alters from positive to negative (Nasrollahi \& Ghaffari goolak, 2010:79).

There are two viewpoints regarding urbanization development effects; the first one declares that the economy structure changed from agricultural basis to industry due to urbanization growth and thus pollution has increased. Although air pollution is attributed to automobile traffic and industrial pollution, another significant factor particularly in large cities is related to nonstandard construction systems and high-rise buildings in downtown and suburbs which block the natural wind paths and accumulate pollutants. The second viewpoint believes that urbanization leads to more efficient infrastructure, transportation system and energy; consequently, energy consumption efficiency in cities is higher than rural areas and pollution decreases. Hence, the correlation between urbanization and environmental pollution might be positive or negative (Alam et al., 2007).

Several experimental studies in term of effective factors on air pollution in different countries were carried out as follows:

Alam et al. (2007) investigated the correlation among economic growth, energy intensity, $\mathrm{CO}_{2}$ emission, population rate, and urbanization in Pakistan by data derived in 1971-2005. The findings demonstrated that increment of $1 \%$ in gross domestic product results in $0.84 \%$ increase in carbon dioxide emission; while increment of $1 \%$ in energy intensity causes $0.24 \%$ increase in carbon dioxide emission. In addition, urbanization development and population growth have significantly made pollution emission, however these two factors decrease economic growth in a long term scale.

Say and Yucel (2006) studied the correlation between energy consumption and $\mathrm{CO}_{2}$ emission in Turkey in the period 19702002. For this purpose, the total energy consumption was estimated by means of economic growth and population growth which are two major factors in energy consumption of developing countries; then, the correlation between total energy consumption and $\mathrm{CO}_{2}$ emission was evaluated by regression analysis. The results indicate a strong correlation between energy consumption and $\mathrm{CO}_{2}$ emission.

Schipper et al. (2009) studied the impacts of transportation sector on carbon dioxide emission in Asian developing countries in 2000 and 2005. It was found out that transportation-related $\mathrm{CO}_{2}$ emission in the developing countries has a greater share compared to the global $\mathrm{CO}_{2}$ emission. Heavy vehicles as trucks consume a large amount of fuel and emit more $\mathrm{CO}_{2}$ than light-weight vehicles; $\mathrm{so}, \mathrm{CO}_{2}$ emission might be directly decreased by transportation system in the development of urban and rural areas.

Gaeser and kahn (2010) in a research entitled as "City greenness: $\mathrm{CO}_{2}$ emission and city development" have analyzed cities development and $\mathrm{CO}_{2}$ emission in various regions across US in 2000. According to the findings, the lowest $\mathrm{CO}_{2}$ emission was related to California; while the highest $\mathrm{CO}_{2}$ emission was observed in Texas and Oklahoma. Besides, there 
is a negative correlation between emissions and land use regulations. In general, $\mathrm{CO}_{2}$ emission is considerably lower in cities compared to suburbs.

Arouri et al. (2012) in a paper entitled as "energy consumption, economic growth, and $\mathrm{CO}_{2}$ emission in middle-east and North African countries" have investigated the correlation between $\mathrm{CO}_{2}$ production, energy consumption, and gross domestic product on twelve middle-east and North African countries in the period 1981-2005. A positive correlation was found between non-renewable energy consumption and $\mathrm{CO}_{2}$ production.

Sebri and Salha (2013) in a study regarding BRICS countries (including Brazil, Russia, India, China, and South Africa) in 1971-2010, found a long-term correlation among economic growth variables, renewable energy consumption, trade openness, and $\mathrm{CO}_{2}$ emission.

Akpan and Abang (2014) surveyed the correlation between environmental quality and economic growth in 47 countries in the period 1970-2008. The findings demonstrated that economic growth, energy price, export to gross domestic product ratio, and energy consumption have a significant positive effect on $\mathrm{CO}_{2}$ emission; while population growth and import to gross domestic product ratio showed a significant negative effect on the pollution.

Shafiei and Salim (2014) in a paper named as "renewable/non-renewable energy consumption and $\mathrm{CO}_{2}$ production in OECD countries" studied the effective factors on $\mathrm{CO}_{2}$ production in these countries in the period 1980-2011. The results denote that $\mathrm{CO}_{2}$ production is decreased by renewable energy consumption whereas non-renewable energy consumption increases greenhouse gas production.

Begum et al. (2015) investigated the dynamic effects of gross domestic product, energy consumption, and $\mathrm{CO}_{2}$ emission in Malaysia. The research findings have not confirmed the Environment Kuznets theory. Study of the destructive effects of economic growth on $\mathrm{CO}_{2}$ emission in long term has been one of the important results of this study.

Asgari and Mohammadi (2016) studied Intra industry trade on air pollution in Iran applying data panel and various industries data in the period 1980-2014. The effects of Intra industries trade in the air pollution in Iran were found to be positive.

\section{4- Data and model prediction}

As seen in Table 1, $\mathrm{CO}_{2}$ had the greatest portion among all polluting greenhouse gases in Iran in 2009-2013; as its value increases from 492 million tons in 2007 to 587 million tons in 2013.

Table 1.

The diffusion of pollution gases from production and consumption energy in Iran 2007-2013

(Ton)

\begin{tabular}{|l|l|l|l|l|}
\hline Year & Co & Nox & So $_{2}$ & $\mathrm{Co}_{2}$ \\
\hline 2007 & 8456502 & 1378957 & 1424973 & 492264957 \\
\hline 2008 & 8973628 & 1808553 & 1598617 & 523293617 \\
\hline 2009 & 8651070 & 1836265 & 1678078 & 538527894 \\
\hline 2010 & 201223 & 1805823 & 1355656 & 532324843 \\
\hline 2011 & 8033989 & 1843831 & 1425800 & 547014571 \\
\hline 2012 & 8523752 & 1861374 & 1540500 & 556866442 \\
\hline 2013 & 9136589 & 1946838 & 1612823 & 587445727 \\
\hline
\end{tabular}

Source: Energy balance sheet, Ministry of power, I.R.I , 2013.

In total, the highest energy consumption in different sectors in Iran was related to oil and natural gas products (about $90 \%$ ); and according to Table 2 , oil products consumption has been decreased while natural gas consumption has been 
increased during the time; however, urbanization rate has been rapidly developed in Iran and has reached more than $70 \%$ nowadays according to statistical center of Iran.

Table 2.

Energy carriers' consumption in domestic, public, commercial, industry, transportation, and agriculture sectors in the period 2006-2013 (million tons petroleum)

\begin{tabular}{|c|c|c|c|c|c|c|}
\hline \multirow[b]{2}{*}{ Year } & \multicolumn{2}{|l|}{ Oil products ${ }^{11}$} & \multicolumn{2}{|c|}{ Natural gas products } & \multicolumn{2}{|l|}{ Electricity } \\
\hline & $\begin{array}{l}\text { Domestic, } \\
\text { Public, } \\
\text { Commercial, } \\
\text { Industry, } \\
\text { Transportation }\end{array}$ & Agriculture & $\begin{array}{l}\text { Domestic, } \\
\text { Public, } \\
\text { Commercial, } \\
\text { Industry, } \\
\text { Transportation }\end{array}$ & Agriculture & $\begin{array}{l}\text { Domestic, } \\
\text { Public, } \\
\text { Commercial, } \\
\text { Industry, } \\
\text { Transportation }\end{array}$ & Agriculture \\
\hline 2006 & 56.2 & 3.6 & 50.7 & 0.1 & 10.1 & 1.4 \\
\hline 2007 & 56.4 & 3.6 & 59.6 & 0.2 & 10.71 & 1.4 \\
\hline 2008 & 57.1 & 3.8 & 59.6 & 0.2 & 11.22 & 1.7 \\
\hline 2009 & 57.2 & 3.9 & 65.2 & 0.3 & 11.82 & 1.7 \\
\hline 2010 & 50.7 & 3.9 & 70.7 & 0.4 & 12.72 & 1.9 \\
\hline 2011 & 46.9 & 3.9 & 78.2 & 0.5 & 12.53 & 2.4 \\
\hline 2012 & 47.7 & 3.3 & 76 & 0.7 & 13.23 & 2.5 \\
\hline 2013 & 48.7 & 3.2 & 80.4 & 0.9 & 13.53 & 2.7 \\
\hline
\end{tabular}

Source: Energy balance sheet, Ministry of power, I.R.I , 2013

If energy consumption by domestic, public, commercial, industry, and transportation sectors is assumed as an indicator of urban consumption and energy consumption by agricultural activities as an indicator of rural consumption, it is observed that the highest energy consumption and pollution were attributed to cities in the period 2006-

2013.

Fossil fuels amount and portion in $\mathrm{CO}_{2}$ emission in 2013 are presented in Table 3. As it is seen, the highest share in $\mathrm{CO}_{2}$ emission was allocated to natural gas.

Table 3.

Fossil fuel amount (Ton) and share (\%) in CO2 emission in 2013.

\begin{tabular}{|l|l|l|l|l|l|l|}
\hline & Liquid gas & Petrol & Kerosene & Gas oil & Fuel oil & Natural gas \\
\hline Quantity & 8335319 & 59460393 & 10695282 & 114314426 & 74171027 & 304924289 \\
\hline Percentage & 1.42 & 10.12 & 1.82 & 19.46 & 12.63 & 51.91 \\
\hline
\end{tabular}

\footnotetext{
1 These products comprise liquid gas, petrol, kerosene, gas oil, and fuel oil.
} 
Source: Energy balance sheet, Ministry of power, I.R.I, 2013.

An econometrics model derived by Alam et al. (2007) was utilized in order to investigate the effective factors on air pollution and measuring their impacts which is expressed as:

PERCO2 $=f(P E R I, S H E, U R B)$

Where:

PERCO 2 : per capita $\mathrm{CO}_{2}$ emission (Ton per person)

PERI: per capita income (constant in 2004)

SHE: energy consumption intensity (ratio of final energy consumption to gross domestic product)

URB: urbanization rate (ratio of urban population to total population)

It should be noted that other variables like per capita oil product consumption and level of industrialization (added value of industry sector out of gross domestic product) were also applied in the model which at last were omitted from the final model due to lack of statistical credit.

The data regarding the variables is in the form of annual time series in the period 1993-2013. In order to avoid the false regression estimations, the statistics of variables must be investigated before model prediction. Augmented Dicky Fuller test (ADF) has been utilized to determine the Stationary of variables.

As seen in Table 4, all variables are static $(I(0))$ and allow for the model prediction by OLS method.

\section{Table 4.}

\section{Report of variables stationary}

\begin{tabular}{|c|c|c|c|c|c|c|}
\hline \multirow{2}{*}{\multicolumn{2}{|c|}{ Variable }} & \multirow{3}{*}{$\begin{array}{l}\text { ADF statistics } \\
2.58\end{array}$} & \multicolumn{3}{|c|}{ Critical value in surface } & \multirow{3}{*}{$\begin{array}{l}\text { Statistical condition } \\
\mathrm{I}(0)\end{array}$} \\
\hline & & & \multirow{2}{*}{$\begin{array}{l}1 \% \\
-2.68 \\
\end{array}$} & \multirow{2}{*}{$\begin{array}{l}5 \% \\
-1.95\end{array}$} & \multirow{2}{*}{$\begin{array}{l}10 \% \\
-1.61 \\
\end{array}$} & \\
\hline Per capita carbon dioxide & $\mathrm{PERCO}_{2}$ & & & & & \\
\hline $\begin{array}{l}\text { Real per capita national } \\
\text { income }\end{array}$ & PERI & 1.79 & -2.75 & -1.97 & -1.6 & $\mathrm{I}(0)$ \\
\hline Energy consumption intensity & SHE & -4.65 & -3.8 & -3.02 & -2.65 & $\mathrm{I}(0)$ \\
\hline Urbanization rate & URB & -4.52 & -3.8 & -3.02 & -2.6 & $\mathrm{I}(0)$ \\
\hline
\end{tabular}

Source: research findings.

The regression estimation of equation (1) is as follows:

$\mathrm{PERCO}_{2}=-15 / 3 \mathrm{C}+0 / 0001 \mathrm{PREI}+0 / 003 \mathrm{SHE}+27 / 8 \mathrm{URB}+0 / 66 \mathrm{AR}(1)$
$\mathrm{t}:$
$(-2 / 6)$
$(2 / 45)$
$(0 / 54)$

$R_{2}=0 / 96 \quad F=82 / 47 \quad$ D.W. $=1 / 66$

As shown by the abovementioned findings, all variables (except for Y-intercept $(C)$ ) had a positive effect on the dependent variable and $96 \%$ of dependent variable changes is explained by independent variables changes, $A R(1)$ is applied for removal the autocorrelation problem of variabes. According to $\mathrm{F}$ statistics, total regression has statistical validity.

The coefficient of real per capita national income (PERI) demonstrated that increment of $1 \%$ in the considered variable causes an increase of $0.0001 \%$ (averagely) in per capita $\mathrm{CO}_{2}$ emission and holds a high statistical credit. Therefore, according to the Environment Kuznets Curve (EKC) - which expresses the correlation between the environmental indices 
and per capita income - the pollution amount has been increased due to the per capita income increase in the studied period in Iran as a developing country.

The coefficient of energy consumption intensity (SHE) indicates that increment of $1 \%$ in the considered variable ends in an increase of $0.003 \%$ (averagely) in per capita $\mathrm{CO}_{2}$ emission; however, this variable does not provide the sufficient statistical credit.

Urbanization rate (URB) is realized as the highest coefficient; in other words, per capita $\mathrm{CO}_{2}$ emission increases by $28 \%$ (averagely) as increment of $1 \%$ occurs in the coefficient; it also has a high statistical credit. As mentioned earlier, numerous viewpoints look differently regarding the effect of this variable on air pollution and are dependent on the urban development structures. This phenomenon has considerably led to air pollution and $\mathrm{CO}_{2}$ emission in Iran.

Effects of the final consumption of major energy carriers on $\mathrm{CO}_{2}$ emission in Iran - in order to evaluate effective factors on air pollution in cities - were estimated according to the model below (assuming energy carriers consumption in domestic, commercial, industry, and transportation sectors are related to urban areas):

PERCO2 $=f(P E R F O, P R E G A, P E R B A)$

Where:

PERCO 2 : per capita $\mathrm{CO}_{2}$ emission (Ton per person)

PERFO: per capita oil product consumption

PERGA: per capita natural gas consumption

PERBA: per capita electricity consumption

After the augmented Dicky Fuller test was carried out to investigate the variables Stationary (the results are shown in appendix), the estimated regression is derived:

PERCO $_{2}=1 / 3 \mathrm{C}+3 / 4$ PREFO+4/04 PERGA (-1)-10/03D (PERBA (-1)) + 0/34 AR (1)
$t$ :
$(2 / 05)$
$(10 / 35)$
$(-0 / 96)$

$R_{2}=0 / 97 \quad F=117 / 8 \quad$ D.W. $=1 / 8$

By abovementioned findings, $97 \%$ of dependent variable changes is explained by independent variables changes. As it was predicted and shown above, per capita oil and natural gas products consumptions have a significant positive effect on $\mathrm{CO}_{2}$ emission while per capita natural gas consumption had a more important effect (4.04\% compared to $\left.3.4 \%\right)$. In other words, in the studied period, an increment of $1 \%$ in per capita oil product consumption made per capita $\mathrm{CO}_{2}$ emission increase by $3.4 \%$ (on average); while an increment of $1 \%$ in per capita natural gas consumption made an increase of $4.04 \%$ (on average) in per capita $\mathrm{CO}_{2}$ emission. In contrast, the coefficient of per capita electricity consumption is negative ( $D$ (PERBA) is $1^{\text {st }}$ difference of PERBA for removal the nonstationary problem), which means $\mathrm{CO}_{2}$ emission decreases as per capita electricity consumption increases; however, the coefficient lacks the required statistical credit.

Therefore, energy sources in Iran - which oil and natural gas products show the greatest shares- were found as the most dominant factors in environmental pollution. $A R(1)$ is applied for removal the autocorrelation problem of variabes.

\section{5- Conclusions and recommendations}

$\mathrm{CO}_{2}$ emission is one of the most principal factors in the environmental pollution; the world efforts are concentrated to reduce it due to its devastating effects on climatic change and global warming. In the current research, the effective factors on air pollution in Iranian cities were studied, considering $\mathrm{CO}_{2}$ emission level as the pollution index in the period 1993-2013. Econometrics models were applied to analyze the effective factors on air pollution in Iran. 
The research findings demonstrated that $1 \%$ increase in real per capita national income averagely led to an increase of 0.0001 in per capita $\mathrm{CO}_{2}$ emission. Hence, according to the Environment Kuznets Curve (EKC) determining the correlation between environmental indices and per capita income, the pollution has been increased as a result of per capita income increase in Iran as a developing country.

The coefficient of energy consumption intensity (SHE) indicates that an increment of $1 \%$ in the considered variable ends in $0.003 \%$ (averagely) increase in per capita $\mathrm{CO}_{2}$ emission; however, this variable does not provide the sufficient statistical credit.

Urbanization rate (URB) is realized as the highest coefficient; in other words, per capita $\mathrm{CO}_{2}$ emission increases by $28 \%$ (averagely) as an increment of $1 \%$ occurs in the coefficient and has a high statistical credit.

Study of the effective factors on cities air pollution in Iran showed that per capita oil and natural gas products consumptions have a significant positive effect on $\mathrm{CO}_{2}$ emission while per capita natural gas consumption had a more important effect (4.04\% compared to $3.4 \%$ ). In other words, in the studied period, in per capita oil product consumption made per capita $\mathrm{CO}_{2}$ emission increase by $3.4 \%$ (on average); while an increment of $1 \%$ in per capita natural gas consumption made an increase of $4.04 \%$ (on average) in per capita $\mathrm{CO}_{2}$ emission. In contrast, the coefficient of per capita electricity consumption is negative which means $\mathrm{CO}_{2}$ emission decreases as per capita electricity consumption increases; however, the coefficient lacks the required statistical credit.

Therefore, energy sources in Iran - which oil and natural gas products show the greatest shares- were found as the most dominant factors in environmental pollution. Thus, the necessity of current energy carriers' replacement by clean energy sources as solar energy and geothermal energy is emphasized.

In addition, automobile manufacturing with high standards and low pollution potentials, improvement of vehicle fuels, utilization of less-polluting energies as electricity in automobile manufacturing process, modification of regulations in large cities, eliminating worn out and nonstandard cars, encouraging people to avoid cars, upgrading public transportation, and setting carbon taxes are other solutions which might play roles in air pollution reduction created by industrialization and urbanization development.

\section{References}

[1] Alam,S.,Fatima,A. and M.Butt(2007),"Sastainable development degradation",Journal of Asian Economics,N.18.

[2] -Akpan,U.F. \& Abang,D.E.(2014),"Environmental quality and economic growth: a panel analysis of the "U" in Kuznets", MPRA Paper N.54461,1-22,Posted 20.

[3] -Arouri,A.Ben Yussef,H.Mhenni,C(2012),"Energy consumption,economic growth and co2 emission Middle East and North African countries",Energy policy,45,pp.126-135.

[4] -Asghari. M., Mohamadi.M.H. , (2016),"Inter - industrial trade on Iran's air pollution", Open Journal of Ecology, 6, pp.277-287.

[5] -Begum,R.A. Sohag.k.,Mastura Syed Abdullah ,S. \& Jaafar ,M. (2015), "CO2 emission, energy consumption, economic and population growth in Malaysia", Renewable and Sustainable Energy Reviews,41,594-601.

[6] Energy balance sheet,(2013), Ministry of power, I.R.I.

[7] -Gaeser, E.L. and Kahn, M.E. (2010), " The greenness of cities: carbon dioxide emission and urban development", journal of urban economics,N. 6, pp. 404-418.

[8] Grossman,G.M. \& Krueger,A.B.(1991),"Environmental impacts of a Norh American free trade agreement", National Bureau of Economic Research, Working Paper,3914,NBER,Cambridge MA.

[9] Karbasi.A, Rahimi.N. (2000)"Environmental considerations energy sector",IEA,pp.2.

[10] Poumanyvong, $P$ and Kaneko, S (2010), "does urbanization lead to less energy use and lower co2 emissions? A cross - country analysis", Ecological Economics, vol. 70 pp. 434-444.

[11] Nasrollahi.Z, Ghaffari goolak.M,( 2010)"Air bollution and factors affectina it (case study, SPM and SO2 emissions in the manufacturing industries of Iran )", Journal of Economic Research,N.3, pp.79. 
[12] Say,N. \& Yucel,M.(2006),"Energy consumption and co2 emissions in Turkey :Empirical analysis and future projection based on an economic growth", Energy policy,34,PP.3870-3876.

[13] Schipper, L., Fabian, H., and Leather, J. (2009); "Transport and carbon Dioxide Emissions: forecasts, Options Analysis and Evaluation", ADB Sustainable Development, Working paper series, pp. 1-41.

[14] Sebri. M.. \& Ben-Salha. O. (2014). "On the causal dvnamics between economic arowth. renewable enerav consumption. CO2 emissions and trade openness: fresh evidence from BRICS countries". Renewable and Sustainable Energy Reviews, 39, PP.14-23.

[15] Shafiei.S..Salim.R.(2014)."Non-renewable and renewable eneray consumption and CO2 emissions in OECD countries: A compatative analysis",Energy policy,66,pp.547-556.

\section{Appendixes}

Null Hypothesis: D(PVAl) has a unit root

Exogenous: Constant

Lag Length: 0 (Automatic - based on AIC, maxlag=4)

\begin{tabular}{llcl}
\hline \hline Prob. $^{*}$ & t-Statistic & & \\
\hline \hline 0.0191 & -3.516648 & Augmented Dickey-Fuller test statistic & \\
\hline & -3.831511 & $1 \%$ level & Test critical values: \\
& -3.029970 & $5 \%$ level & \\
& -2.655194 & $10 \%$ level & \\
\hline \hline
\end{tabular}

*MacKinnon (1996) one-sided p-values.

Null Hypothesis: SHE has a unit root

Exogenous: Constant

Lag Length: 0 (Automatic - based on AIC, maxlag=4)

\begin{tabular}{lccc}
\hline \hline Prob. & t-Statistic & & \\
\hline \hline 0.0016 & -4.652855 & Augmented Dickey-Fuller test statistic & \\
\hline & -3.808546 & $1 \%$ level & Test critical values: \\
& -3.020686 & $5 \%$ level & \\
& -2.650413 & $10 \%$ level & \\
\hline \hline
\end{tabular}

*MacKinnon (1996) one-sided p-values.

Null Hypothesis: PERCO2 has a unit root

Exogenous: None

Lag Length: 0 (Automatic - based on AIC, maxlag=4)

\begin{tabular}{lll}
\hline \hline Prob.* $^{*}$ & t-Statistic & \\
\hline \hline 0.9978 & 2.854703 & Augmented Dickey-Fuller test statistic \\
\hline
\end{tabular}




$\begin{array}{lll}-2.685718 & 1 \% \text { level } & \text { Test critical values: } \\ -1.959071 & 5 \% \text { level } & \\ -1.607456 & 10 \% \text { level } & \end{array}$

*MacKinnon (1996) one-sided p-values.

Null Hypothesis: URB has a unit root

Exogenous: Constant

Lag Length: 0 (Automatic - based on AIC, maxlag=4)

\begin{tabular}{lccc}
\hline \hline Prob.* & t-Statistic & & \\
\hline \hline 0.0022 & -4.520363 & Augmented Dickey-Fuller test statistic & \\
\hline & -3.808546 & $1 \%$ level & Test critical values: \\
& -3.020686 & $5 \%$ level & \\
& -2.650413 & $10 \%$ level & \\
\hline \hline
\end{tabular}

*MacKinnon (1996) one-sided p-values.

Null Hypothesis: PERFO has a unit root

Exogenous: Constant, Linear Trend

Lag Length: 4 (Automatic - based on t-statistic, lagpval=0.1, maxlag=4)

\begin{tabular}{llll}
\hline \hline Prob.* $^{*}$ & t-Statistic & & \\
\hline \hline 0.0890 & -3.383928 & Augmented Dickey-Fuller test statistic & \\
\hline & -4.667883 & $1 \%$ level & Test critical values: \\
& -3.733200 & $5 \%$ level & \\
& -3.310349 & $10 \%$ level & \\
\hline \hline
\end{tabular}

*MacKinnon (1996) one-sided p-values.

Warning: Probabilities and critical values calculated for 20 observations

and may not be accurate for a sample size of 16

Null Hypothesis: PERBA has a unit root

Exogenous: Constant, Linear Trend

Lag Length: 0 (Automatic - based on t-statistic, lagpval=0.1, maxlag=4)

\begin{tabular}{llcl}
\hline \hline Prob.* & t-Statistic & & \\
\hline \hline 0.7618 & -1.586284 & Augmented Dickey-Fuller test statistic & \\
\hline & -4.498307 & $1 \%$ level & Test critical values: \\
& -3.658446 & $5 \%$ level & \\
& -3.268973 & $10 \%$ level & \\
\end{tabular}


*MacKinnon (1996) one-sided p-values.

Null Hypothesis: D(PERBA) has a unit root

Exogenous: Constant

Lag Length: 0 (Automatic - based on t-statistic, lagpval=0.1, maxlag=4)

\begin{tabular}{llcl}
\hline \hline Prob.* $^{*}$ & t-Statistic & & \\
\hline \hline 0.0435 & -3.102083 & Augmented Dickey-Fuller test statistic & \\
\hline & -3.831511 & $1 \%$ level & Test critical values: \\
& -3.029970 & $5 \%$ level & \\
& -2.655194 & $10 \%$ level & \\
\hline \hline
\end{tabular}

*MacKinnon (1996) one-sided p-values.

Warning: Probabilities and critical values calculated for 20 observations and may not be accurate for a sample size of 19

Dependent Variable: PERCO2

Method: Least Squares

Date: 08/03/16 Time: 23:39

Sample (adjusted): 13751392

Included observations: 18 after adjustments

Convergence achieved after 10 iterations

\begin{tabular}{lllll}
\hline \hline Prob. & t-Statistic & Std. Error & Coefficient & Variable \\
\hline \hline 0.0609 & 2.051644 & 0.637271 & 1.307453 & C \\
0.0124 & 2.900357 & 1.174519 & 3.406525 & PERFO \\
0.0000 & 10.35659 & 0.390435 & 4.043574 & PERGA(-1) \\
0.3533 & -0.962640 & 10.42316 & -10.03375 & D(PERBA(-1)) \\
0.2303 & 1.258535 & 0.270804 & 0.340817 & AR(1) \\
\hline \hline \multirow{2}{*}{5.660819} & Mean dependent var & 0.973164 & R-squared \\
1.462727 & S.D. dependent var & 0.964907 & Adjusted R-squared \\
0.478859 & Akaike info criterion & 0.274014 & S.E. of regression \\
0.726184 & Schwarz criterion & 0.976088 & Sum squared resid \\
0.512962 & Hannan-Quinn criter. & 0.690272 & Log likelihood \\
1.813168 & Durbin-Watson stat & 117.8572 & F-statistic \\
& & 0.000000 & Prob(F-statistic) \\
\hline \hline
\end{tabular}

